\title{
Effect of Laparoscopic Sleeve Gastrectomy on Type 2 Diabetes Mellitus Obese Patients
}

\author{
Youhanna Shohdy Shafik, MD; MRCS (Eng); ${ }^{1}$ John Adel Sedkey, ${ }^{1}$ Sherif AbdelHalim, \\ MD; ${ }^{1}$ Hany Aly Hussein, MD² \\ ${ }^{1}$ Department of General Surgery, Faculty of Medicine. ${ }^{2}$ Department of Internal Medicine, Faculty of Medicine, \\ Ain Shams University, Cairo, Egypt
}

Background: Type 2 diabetes mellitus represents high proportion of diabetics which is mainly due to obesity and insulin resistance. Obesity is asscoiated with many co-morbidities like type $2 \mathrm{DM}$, cardiovascular (CV) complications, hypertension and dyslipidymia. Laparoscopic sleeve gastrectomy (LSG) was used as the first stage in a multistage procedure in obese patients with at least two severe co-morbidities. Two years after sleeve gastrectomy, more than $50 \%$ of those patients showed resolution of their co morbidities. Bariatric surgery has emerged as a highly effective management for morbid obesity and many related co-morbidities, including type 2 diabetes mellitus (T2DM). However, it has recently been approved that LSG is more than a gastric restrictive operation. It has been suggested that the changes in ghrelin and peptide YY after LSG may help to explain the weight loss results. So the aim of this study was to evaluate the effect of laparoscopic sleeve gastrectomy (LSG) on obese patients with type 2 DM.

Methods: This study was conducted on 30 obese patients suffering from T2DM ( 9 males and 21 females) who underwent laparoscopic sleeve gastrectomy at the Ain Shams University Hospital (El-Demerdash) and Ain Shams Specialized Hospital. Follow up of the patients was done for a period of 6 months to investigate their HbA1c changes and diabetic status.

Results: Our results showed significant reduction in the mean level of HbA1c $(p<0.001)$ at 6 months follow-up post-surgery, with $16.7 \%$ (5 patients) completely cured from T2DM while $40 \%$ (12 patients) became pre-diabetic and $43.3 \%$ (13 patients) remained diabetic.

Conclusion: Most patients with type 2 DM experience resolution or improvement in diabetic status after LSG. LSG might play an important role as a metabolic therapy for patients with type 2 DM.

Key words: Obesity- type 2 diabetes mellitus- Laparoscopic sleeve gastrectomy.

\section{Introduction}

Type 2 diabetes mellitus and obesity are assumed to be two major public health problems worldwide nowadays. Vascular complications are thought to be the leading cause of disability in diabetics. The high cardiovascular (CV) risk that diabetes induces is better explained by approaching not only hyperglycemia but also the usual coexisting risk factors. ${ }^{1}$

Better glucose control with lowering hemoglobin A1c (HbA1c) value to $6.5 \%$ yielded a $10 \%$ relative reduction in major macrovascular and microvascular events. However, in another study, an intensive glucose control in patients with poorly controlled T2DM had no significant effect on the number of major CV events, deaths, or microvascular complications. ${ }^{1}$

Remission of type 2 DM can be achieved by surgical procedures in the majority of morbidly obese patients. ${ }^{1}$

Bariatric surgery is starting to be effective and long-lasting treatment for morbid obesity and many related conditions, including type 2 diabetes mellitus (T2DM) and the metabolic syndrome $(\mathrm{MS}){ }^{2}$

LSG is a surgical procedure, by which a laparoscopic vertical gastrectomy is done, that excises the fundus and the lateral $80 \%$ of the gastric body leaving a tubular-like stomach with an intact pylorus. ${ }^{1}$

Since its introduction, the procedure has gained acceptance due to its simplicity, good results in weight lost, and less complication. ${ }^{1}$

The aim of this operation is to remove a part of the stomach in order to provide long-lasting control of obesity, to decrease caloric intake, to accelerate gastric emptying, and to decrease the circulating levels of ghrelin Hormone. ${ }^{1}$

This surgery is associated with increase in insulin sensitivity and $B$ cell function which could be related to decrease ghrelin levels postoperatively and these results have been compared to nonresection restrictive procedures like adjustable gastric banding. Therefore, it is assumed that the final effect of procedures involving gastric 
transection decreases the serum ghrelin levels and improves insulin sensitivity. ${ }^{3}$

The other characteristic of the operation is to correct the defective amplification of the latephase plasma insulin response to glucose by (glucose-dependent insulinotropic polypeptide) (GIP). Both characteristics were addressed in a recent publication of the hormonal changes before and after LSG. ${ }^{1}$

Also, data collected have shown that Sleeve Gastrectomy (GS) is associated with a high rate of resolution of T2DM and other obesity related co-morbidities such as hypertension, hyperlipidemia, and sleep apnea. ${ }^{4}$

\section{Aim of the work}

To determine the effect of LSG on blood glucose level in type 2 diabetic obese Egyptian patients.

\section{Patients and methods \\ - Patients:}

This prospective study was conducted on thirty obese Egyptian patients with type 2 diabetes mellitus that underwent LSG at the Ain Shams University Hospital (El-Demerdash) and Ain Shams Specialized Hospital. All the patients met the inclusion/exclusion criteria followed the by the National Institute of Health (NIH) Bariatric guidelines. ${ }^{5}$

Inclusion criteria: were type 2 diabetic obese patients aged more than 18 years old, BMI $\geq$ $35 \mathrm{~kg} / \mathrm{m} 2$ with duration of diabetes $>1$ year, glycated hemoglobin $(\mathrm{HbA} 1 \mathrm{c}) \geq 6.5 \%$, receiving either oral hypoglycemic drugs $(\mathrm{OHG})$ or insulin or $\mathrm{OHG}+$ insulin.

Exclusion criteria: were type 1 diabetic patients, glycated hemoglobin (HbA1c) $<6.5 \%$, age $<18$ years, BMI $<35 \mathrm{~kg} / \mathrm{m} 2$, endocrine obesity, a history of medical problems such as mental impairment, drug or alcohol addiction and patients who had previous bariatric surgeries.

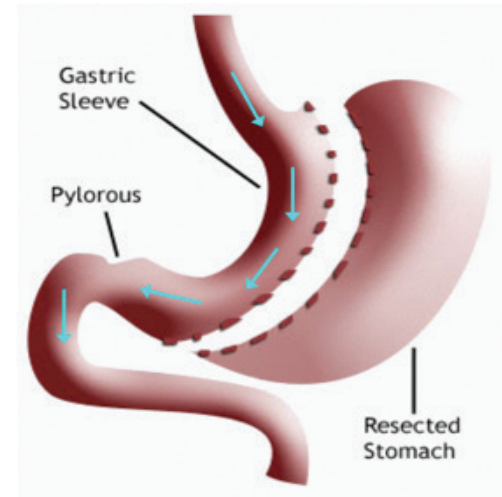

Fig 1: Diagram show Sleeve gastrectomy procedure. ${ }^{7}$
- Methods:

1. Preoperative evaluation: The preoperative evaluation included discussing in detail the risks, benefits and long-term consequences of the procedures during the initial encounter with the surgeon, internist and dietician. All patients were examined by a medical team consisting of an internist, a bariatric surgeon, a psychiatrist, and a dietician. All patients were subjected to the following: Full history taking, clinical examination, calculation of body mass index (BMI), ${ }^{6}$ and laboratory investigations including: complete blood picture, liver function tests, renal functions tests, hepatitis markers (HBsAg and HCVAb), glycated hemoglobin (HbA1c) and fasting blood sugar on day of operation. Written informed consent was obtained from all patients before being assigned to surgery.

2. Operative technique: Surgical technique LSG was performed according to the technique described by Gagner ${ }^{7}$ - Division of the gastric greater curvature vascular supply, starting at $6-8 \mathrm{~cm}$ from the pylorus and proceeding upwards until the angle of His, was carried out with Harmonic Scalpel, (Ethicon). The LSG was created using a linear stapler Endo GIA, with two sequential $60-\mathrm{mm}$ green load firings for the antrum, followed by two or three sequential $60-\mathrm{mm}$ blue loads for the remaining gastric corpus and fundus. The stapler was applied alongside a $36 \mathrm{Fr}$ calibrating bougie strictly positioned against the lesser curve, to obtain a $120-150 \mathrm{ml}$ gastric pouch. The resected stomach was extracted by enlargement of the $15-\mathrm{mm}$ port-site. Abdominal drainage was left in place.

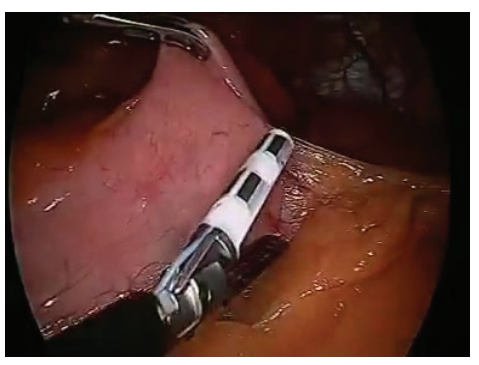

A1

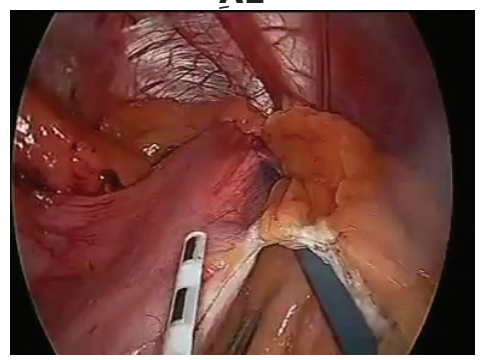

A2

Figs: 2A1,A2 The division of the gastric greater curvature vascular supply, starting at $6-8 \mathrm{~cm}$ from the pylorus. 


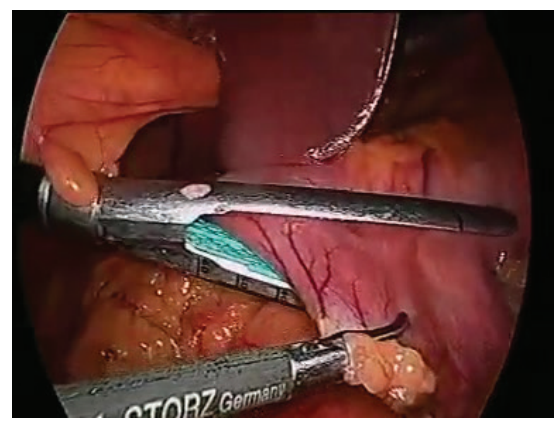

B1

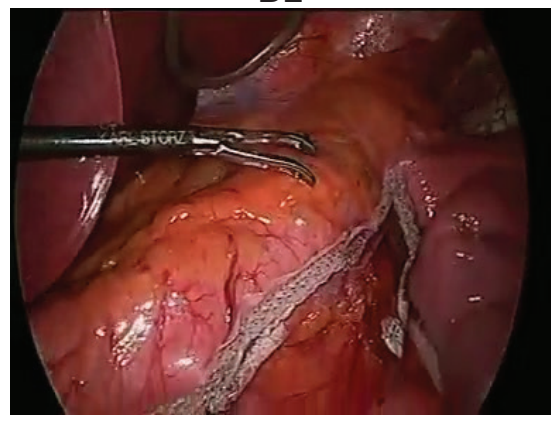

B2

Figs: 3B1,B2 The LSG is created using a linear stapler (Endo GIA).

3. Postoperative care: All patients were monitored in the recovery room and were transferred to the wards or to the intensive care unit. Early postoperative ambulation was strongly encouraged with patients getting out of bed the evening of the surgery and walking by the first postoperative day. A clear liquid diet was started on first postoperative day, and was advanced to pureed food 2 weeks later, and to solid food by the fourth postoperative week. Patients were advised to take daily multivitamins and supplemental minerals, as well as proton pomp inhibitor (PPI) prophylaxis for 6 months. Follow-up appointments with the internist, surgeon and the dietitian were scheduled at second week, 3, and 6 months postoperatively, with six months follow up of (HbA1c) after laparoscopic sleeve gastrectomy with assessment at $0,3,6$ months interval. Patients were grouped to non-diabetic (HbA1c $<5.7 \%)$, pre- diabetic (HbA1c 5.7\%$6.4 \%)$, and diabetics $(\mathrm{HbA} 1 \mathrm{c} \geq 6.5 \%$ ) at 6 month of follow up.

\section{Statistical analysis:}

The collected data was revised, coded, tabulated and introduced to a PC using Statistical package for Social Science (SPSS 19.0.1 for windows; SPSS Inc, Chicago, IL, 2001). Quantitative data was presented as Mean and Standard deviation $( \pm S D)$ while number and percentage was used to present qualitative data. Fisher exact test was used to analyze qualitative data. Repeated measure ANOVA was used to analyze quantitative data measured more than two times for one group, with Bonferroni post hoc test for pair wise comparisons. Friedman test was used to analyze quantitative data measured more than two times for one group. ANOVA was used to analyze quantitative data measured between more than two groups. $P$ Value $<0.05$ will be considered statistically significant.

\section{Results \\ 1-Descriptive data:}

Patients' descriptive data are described in Table 1. This study was conducted on 21 Females (70\%) and 9 males (30\%), their mean age was $33.6 \pm 10.51$ years, range (18-58). The mean preoperative weight was $137.87 \pm 21.28 \mathrm{Kg}$ (range $101-166 \mathrm{Kg}$ ). The mean pre-operative body mass index was $44.91 \pm 5.49 \mathrm{Kg} / \mathrm{m}^{2}$ (range $36-55 \mathrm{Kg} /$ $\mathrm{m}^{2}$ ) as shown in Table 2. Regarding pre-operative hypoglycemic medications, 20 patients $(66.7 \%)$ were on OHG, 6 patients (20\%) on insulin and 4 patients $(13.3 \%)$ on both OHG + insulin as shown in Table 2 and Figure 4.

The mean pre-operative fasting blood sugar (FBS) on the day of surgery was 197.53 \pm 35.2 $\mathrm{mg} / \mathrm{dl}$, range (120-283 mg/dl), with mean HbA1c $7.95 \pm 0.88 \%$, range (6.55-10.2\%). At 3 months follow-up, there was decline in the mean of HbA1c; it reached $7.27 \pm 0.77 \%$, range (5.8-9.14\%). At 6 months follow-up, much more decline occurred in the mean of $\mathrm{HbA1c}$; it reached $6.47 \pm 0.75 \%$, range (5.16-8.6\%) as shown in Table 3.

30 T2DM patients who underwent LSG were enrolled in this study; on follow up at 3 months, 4 patients $(13.3 \%)$ became pre-diabetic and 26 patients $(86.7 \%)$ remained diabetic. At 6 months follow up, more improvement occurred, 5 patients $(16.7 \%)$ became non- diabetic, 12 patients $(40 \%)$ became pre-diabetic and 13 patients (43.3\%) remained diabetic as shown in Table 4.

\section{2-Comparitive data:}

Comparison between the mean values of $\mathrm{HbA1C}$ at 0, 3, 6 months follow-up among patients who underwent LSG; revealed a highly significant reduction $(p=0.0001)$ in the mean value of $\mathrm{HbA1c}$ at 3 months and at 6 months as shown in Table 5 and Fig. 5.

Follow up of diabetic status of patients for 6 months after LSG revealed a highly significant reduction in the number of diabetic patients $(\mathrm{HbA} 1 \mathrm{c} \geq 6.5 \%)$ reaching $43.3 \%(p=0.001)$ as shown in Table 6.

In terms of treatment based outcomes, patients who were on OHG (pre-operative) showed better reduction in the mean of value of $\mathrm{HbA} 1 \mathrm{c}$ $(6.39 \pm 0.77 \%)$ than those on insulin $(6.59 \pm 0.82 \%)$ and $\mathrm{OHG}+$ insulin $(6.74 \pm 0.63 \%)$ at the 6 months 
follow up as shown in Table 7 and Figure 6.

Moreover, better reduction in the number of diabetic patients who were on OHG (35\%) than those on insulin (66.7\%) and $\mathrm{OHG}+$ insulin (50\%) at the 6 months follow up was noted. However, these differences lacked statistical significance with $\mathrm{p}=0.643,0.695$ respectively as shown in Table 7 .

Table 1: Studied Patients` descriptive data

\begin{tabular}{|c|c|c|c|c|c|c|c|c|c|}
\hline No & Age & Gender & $\begin{array}{l}\text { Weight } \\
\text {.in kgs }\end{array}$ & BMI & $\begin{array}{c}\text { Type of anti } \\
\text { diabetic } \\
\text { treatment }\end{array}$ & $\begin{array}{c}\text { FBS on } \\
\text { surg. day }\end{array}$ & $\begin{array}{l}\text { HbA1c } \\
0 \text { Month }\end{array}$ & $\begin{array}{c}\text { HbA1c } \\
3 \text { Months }\end{array}$ & $\begin{array}{l}\text { HbA1c } \\
6 \text { Months }\end{array}$ \\
\hline 1 & $55 y$ & Female & $130 \mathrm{kgs}$ & 42 & OHG & $220 \mathrm{mg} / \mathrm{dl}$ & $7 \%$ & $6.5 \%$ & $5.6 \%$ \\
\hline 2 & $35 y$ & Female & $140 \mathrm{kgs}$ & 46 & INSULIN & $181 \mathrm{mg} / \mathrm{dl}$ & $8.26 \%$ & $5.8 \%$ & $5.16 \%$ \\
\hline 3 & $58 y$ & Female & $120 \mathrm{kgs}$ & 41.5 & $\mathrm{OHG}$ & $120 \mathrm{mg} / \mathrm{dl}$ & $7.4 \%$ & $6.8 \%$ & $5.8 \%$ \\
\hline 4 & $40 y$ & Female & $101 \mathrm{kgs}$ & 37 & OHG & $171 \mathrm{mg} / \mathrm{dl}$ & $7.3 \%$ & $7.1 \%$ & $6.4 \%$ \\
\hline 5 & $37 y$ & Female & $109 \mathrm{kgs}$ & 36.8 & OHG & $162 \mathrm{mg} / \mathrm{dl}$ & $8.2 \%$ & $7.3 \%$ & $6.7 \%$ \\
\hline 6 & $37 y$ & Female & $124 \mathrm{kgs}$ & 41.75 & $\mathrm{OHG}$ & $200 \mathrm{mg} / \mathrm{dl}$ & $7.8 \%$ & $7.12 \%$ & $6.4 \%$ \\
\hline 7 & $44 y$ & Female & $162 \mathrm{kgs}$ & 52 & OHG+insulin & $190 \mathrm{mg} / \mathrm{dl}$ & $7.7 \%$ & $7.2 \%$ & $6.15 \%$ \\
\hline 8 & $21 y$ & Female & $164 \mathrm{kgs}$ & 51 & $\mathrm{OHG}$ & $202 \mathrm{mg} / \mathrm{dl}$ & $7.4 \%$ & $7.16 \%$ & $6.2 \%$ \\
\hline 9 & $38 y$ & Female & $107 \mathrm{kgs}$ & 37.5 & OHG & $183 \mathrm{mg} / \mathrm{dl}$ & $7.8 \%$ & $7.22 \%$ & $6.3 \%$ \\
\hline 10 & $43 y$ & Female & $128 \mathrm{kgs}$ & 43 & $\mathrm{OHG}$ & $203 \mathrm{mg} / \mathrm{dl}$ & $7.6 \%$ & $7.4 \%$ & $6.8 \%$ \\
\hline 11 & $23 y$ & Female & $128 \mathrm{kgs}$ & 44.2 & OHG & $160 \mathrm{mg} / \mathrm{dl}$ & $9 \%$ & $8.23 \%$ & $7.6 \%$ \\
\hline 12 & $30 y$ & Male & $160 \mathrm{kgs}$ & 49 & INSULIN & $196 \mathrm{mg} / \mathrm{dl}$ & $7.4 \%$ & $7.1 \%$ & $7 \%$ \\
\hline 13 & $26 y$ & Male & $150 \mathrm{kgs}$ & 48.2 & INSULIN & $154 \mathrm{mg} / \mathrm{dl}$ & $8.7 \%$ & $8 \%$ & $7.2 \%$ \\
\hline 14 & $18 y$ & Female & $133 \mathrm{~kg}$ & 43 & $\mathrm{OHG}$ & $240 \mathrm{mg} / \mathrm{dl}$ & $7.3 \%$ & $6.44 \%$ & $5.3 \%$ \\
\hline 15 & $30 y$ & Male & $154 \mathrm{kgs}$ & 47.8 & INSULIN & $220 \mathrm{mg} / \mathrm{dl}$ & $8 \%$ & $7.6 \%$ & $6.5 \%$ \\
\hline 16 & $27 y$ & Female & $160 \mathrm{kgs}$ & 49.5 & $\mathrm{OHG}$ & $207 \mathrm{mg} / \mathrm{dl}$ & $7.4 \%$ & $7 \%$ & $6.5 \%$ \\
\hline 17 & $22 y$ & Female & $131 \mathrm{kgs}$ & 41 & INSULIN & $193 \mathrm{mg} / \mathrm{dl}$ & $9.4 \%$ & $8.1 \%$ & $7.40 \%$ \\
\hline 18 & $36 y$ & Male & $140 \mathrm{kgs}$ & 45 & OHG & $223 \mathrm{mg} / \mathrm{dl}$ & $8.55 \%$ & $7.8 \%$ & $6.7 \%$ \\
\hline 19 & $28 y$ & Male & $165 k g s$ & 52.3 & $\mathrm{OHG}$ & $194 \mathrm{mg} / \mathrm{dl}$ & $7.6 \%$ & $7.1 \%$ & $6.2 \%$ \\
\hline 20 & $43 y$ & Female & $108 \mathrm{kgs}$ & 38 & $\mathrm{OHG}$ & $176 \mathrm{mg} / \mathrm{dl}$ & $7.2 \%$ & $6.9 \%$ & $6.4 \%$ \\
\hline 21 & $39 y$ & Female & $166 \mathrm{kgs}$ & 55 & OHG & $283 \mathrm{mg} / \mathrm{dl}$ & $10.2 \%$ & $9.14 \%$ & $8.6 \%$ \\
\hline 22 & $23 y$ & Female & $105 \mathrm{kgs}$ & 36 & OHG+insulin & $172 \mathrm{mg} / \mathrm{dl}$ & $7.2 \%$ & $7 \%$ & $6.4 \%$ \\
\hline 23 & $46 y$ & Male & $148 \mathrm{kgs}$ & 47 & $\mathrm{OHG}$ & $186 \mathrm{mg} / \mathrm{dl}$ & $7.4 \%$ & $7.1 \%$ & $6.2 \%$ \\
\hline 24 & $32 y$ & Female & $155 \mathrm{kgs}$ & 49 & OHG & $258 \mathrm{mg} / \mathrm{dl}$ & $9 \%$ & $8.25 \%$ & $6.8 \%$ \\
\hline 25 & $28 y$ & Male & $157 \mathrm{kgs}$ & 49.5 & OHG & $222 \mathrm{mg} / \mathrm{dl}$ & $7.23 \%$ & $6.9 \%$ & $6.4 \%$ \\
\hline 26 & $45 y$ & Female & $122 \mathrm{kgs}$ & 41 & $\mathrm{OHG}$ & $132 \mathrm{mg} / \mathrm{dl}$ & $7.2 \%$ & $6.4 \%$ & $5.5 \%$ \\
\hline 27 & $24 y$ & Female & $166 \mathrm{kgs}$ & 54 & INSULIN & $202 \mathrm{mg} / \mathrm{dl}$ & $8.3 \%$ & $7.16 \%$ & $6.3 \%$ \\
\hline 28 & $40 y$ & Male & $145 \mathrm{kgs}$ & 44.75 & OHG+insulin & $244 \mathrm{mg} / \mathrm{dl}$ & $9.9 \%$ & $8.2 \%$ & $7.6 \%$ \\
\hline 29 & $21 y$ & Male & $151 \mathrm{kgs}$ & 47.5 & OHG+insulin & $232 \mathrm{mg} / \mathrm{dl}$ & $8.5 \%$ & $7.88 \%$ & $6.8 \%$ \\
\hline 30 & $19 y$ & Female & $107 \mathrm{kgs}$ & 37 & $\mathrm{OHG}$ & $200 \mathrm{mg} / \mathrm{dl}$ & $6.55 \%$ & $6.1 \%$ & $5.3 \%$ \\
\hline
\end{tabular}

Table 2: Personal and medical data of the studied patients underwent Laparoscopic Sleeve Gastrectomy (LSG)

\begin{tabular}{|c|c|c|c|c|c|}
\hline & & Mean & SD \pm & Minimum & Maximum \\
\hline \multicolumn{2}{|l|}{ Age } & 33.60 & 10.51 & 18.00 & 58.00 \\
\hline \multicolumn{2}{|l|}{ Weight } & 137.87 & 21.28 & 101.00 & 166.00 \\
\hline \multirow{2}{*}{\multicolumn{2}{|c|}{ BMI }} & 44.91 & 5.49 & 36.00 & 55.00 \\
\hline & & $\mathrm{N}$ & $\%$ & & \\
\hline \multirow{2}{*}{ Gender } & Male & 9 & $30.0 \%$ & & \\
\hline & Female & 21 & $70.0 \%$ & & \\
\hline \multirow{3}{*}{$\begin{array}{l}\text { Pre-operative hypogly- } \\
\text { cemic medications }\end{array}$} & $\mathrm{OHG}$ & 20 & $66.7 \%$ & & \\
\hline & Insulin & 6 & $20.0 \%$ & & \\
\hline & $\mathrm{OHG+Insulin}$ & 4 & $13.3 \%$ & & \\
\hline
\end{tabular}


$13.3 \%$

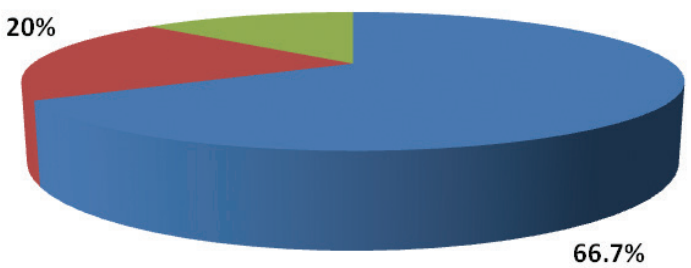

Treatment

घHG Insulin $\quad$ OHG+Insulin

Fig 4: Description of the pre-operative hypoglycemic treatment of the studied patients underwent LSG.

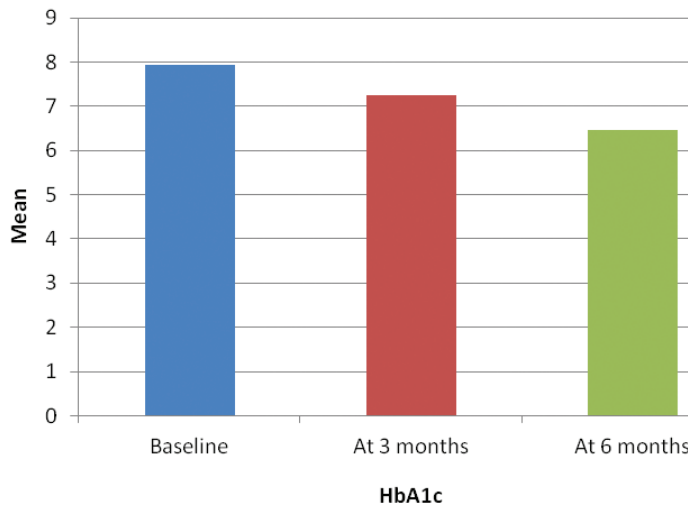

Fig 5: Comparison between mean values of HbA1c at 0, 3, and 6 months follow up postoperative.

Table 3: Description of FBS (preoperative) and HbA1c changes at 0, 3, and 6 months follow up among patients underwent LSG

\begin{tabular}{lcccc}
\hline & Mean & SD \pm & Minimum & Maximum \\
\hline FBS on surgey day & 197.53 & 35.20 & 120.00 & 283.00 \\
HbA1c 0 month & 7.95 & 0.88 & 6.55 & 10.20 \\
HbA1c 3 months & 7.27 & 0.71 & 5.80 & 9.14 \\
HbA1c 6 months & 6.47 & 0.75 & 5.16 & 8.60 \\
\hline
\end{tabular}

Table 4: Description of diabetic status at 0, 3, and 6 months follow up among patients underwent LSG

\begin{tabular}{|c|c|c|c|}
\hline & & $\mathbf{N}$ & $\%$ \\
\hline & $\begin{array}{c}\text { Non Diabetics } \\
(\% \text { HbA1c < 5.7) }\end{array}$ & 0 & $0.0 \%$ \\
\hline \multirow[t]{3}{*}{ HbA1c 0 month } & $\begin{array}{c}\text { Pre Diabetic } \\
(\% \text { HbA1c } 5.7-6.4)\end{array}$ & 0 & $0.0 \%$ \\
\hline & $\begin{array}{c}\text { Diabetic } \\
(\% \text { HbA1c } \geq 6.5)\end{array}$ & 30 & $100.0 \%$ \\
\hline & $\begin{array}{l}\text { Non Diabetics } \\
(\% \mathrm{HbA} 1 \mathrm{c}<5.7)\end{array}$ & 0 & $0.0 \%$ \\
\hline \multirow[t]{3}{*}{ HbA1c 3 months } & $\begin{array}{c}\text { Pre Diabetic } \\
\text { (\% HbA1c } 5.7-6.4 \text { ) }\end{array}$ & 4 & $13.3 \%$ \\
\hline & $\begin{array}{c}\text { Diabetic } \\
(\% \text { HbA1c } \geq 6.5)\end{array}$ & 26 & $86.7 \%$ \\
\hline & $\begin{array}{l}\text { Non Diabetics } \\
(\% \mathrm{HbA} 1 \mathrm{c}<5.7)\end{array}$ & 5 & $16.7 \%$ \\
\hline \multirow[t]{2}{*}{ HbA1c 6 months } & $\begin{array}{c}\text { Pre Diabetic } \\
(\% \text { HbA1c } 5.7-6.4)\end{array}$ & 12 & $40.0 \%$ \\
\hline & $\begin{array}{c}\text { Diabetic } \\
(\% \text { HbA1c } \geq 6.5)\end{array}$ & 13 & $43.3 \%$ \\
\hline
\end{tabular}


Table 5: Comparison between mean values of HbA1c at 0, 3, and 6 months follow up among patients underwent LSG

\begin{tabular}{|c|c|c|c|c|c|}
\hline & Mean & SD士 & $\mathbf{P}$ & Sig & post hoc test \\
\hline $\begin{array}{l}\text { HbA1c } 0 \text { month } \\
\text { (pre-operative) }\end{array}$ & $7.94 \%$ & $0.88 \%$ & & & $\begin{array}{c}\text { HbA1c 0M Vs HbA1c 3M } \\
(H S)\end{array}$ \\
\hline HbA1c 3 months & $7.26 \%$ & $0.71 \%$ & 0.0001 & $\mathrm{HS}$ & $\begin{array}{c}\text { HbA1c 0M Vs HbA1c 6M } \\
(H S)\end{array}$ \\
\hline HbA1c 6 months & $6.47 \%$ & $0.74 \%$ & & & $\begin{array}{c}\text { HbA1c 3M Vs HbA1c 6M } \\
(H S)\end{array}$ \\
\hline
\end{tabular}

$\mathrm{HS}=$ highly significant

Table 6: Comparison between preoperative, 3 months and 6 months post-operative diabetic status among patients underwent LSG

\begin{tabular}{|c|c|c|c|c|c|c|c|c|c|}
\hline & & \multicolumn{2}{|c|}{$\begin{array}{c}\text { month } 0 \\
\text { (pre-operative) }\end{array}$} & \multirow{2}{*}{$\begin{array}{c}3 \\
\text { month } \\
\mathbf{N}\end{array}$} & \multicolumn{3}{|c|}{ month 6} & \multirow[t]{2}{*}{$\mathbf{P}$} & \multirow{2}{*}{ Sig } \\
\hline & & $\mathbf{N}$ & $\%$ & & $\%$ & $\mathbf{N}$ & $\%$ & & \\
\hline \multirow{3}{*}{$\mathrm{HbA1c}$} & $\begin{array}{c}\text { Non Diabetics } \\
(\mathrm{HbA} 1 \mathrm{c}<5.7 \%)\end{array}$ & 0 & $0.0 \%$ & 0 & $0.0 \%$ & 5 & $16.7 \%$ & \multirow{3}{*}{0.001} & \multirow{3}{*}{ HS } \\
\hline & $\begin{array}{c}\text { Pre Diabetic } \\
\text { (HbA1c } 5.7 \quad 6.4 \%)\end{array}$ & 0 & $0.0 \%$ & 4 & $13.3 \%$ & 12 & $40.0 \%$ & & \\
\hline & $\begin{array}{c}\text { Diabetic } \\
(\mathrm{HbA} 1 \mathrm{c} \geq 6.5 \%)\end{array}$ & 30 & $100.0 \%$ & 26 & $86.7 \%$ & 13 & $43.3 \%$ & & \\
\hline
\end{tabular}

$\mathrm{HS}=$ highly significant

Table 7: Comparison between patients with different treatment regimen as regard mean level of HBA1c and diabetic status at $\mathbf{6}$ months follow up after LSG

\begin{tabular}{|c|c|c|c|c|c|c|c|c|c|}
\hline & \multirow{3}{*}{ OHG } & \multicolumn{6}{|c|}{ Treatment } & \multirow{3}{*}{$\mathbf{P}$} & \multirow{3}{*}{ Sig } \\
\hline & & & Ins & lin & OHG + & insulin & & & \\
\hline & & Mean & SD士 & Mean & SD士 & Mean & SD士 & & \\
\hline \multirow[t]{2}{*}{ HbA1c 6M } & & 6.39 & 0.77 & 6.59 & 0.82 & 6.74 & 0.63 & $* 0.643$ & NS \\
\hline & & $\mathbf{N}$ & $\%$ & $\mathbf{N}$ & $\%$ & $\mathbf{N}$ & $\%$ & & \\
\hline \multirow{3}{*}{$\mathrm{HbA1c} 6 \mathrm{M}$} & $\begin{array}{l}\text { Non Diabetics } \\
(\% \text { HbA1c < 5.7) }\end{array}$ & 4 & $20.0 \%$ & 1 & $16.7 \%$ & 0 & $0 \%$ & & \\
\hline & $\begin{array}{l}\text { Pre Diabetic } \\
(\% \text { HbA1c 5.7-6.4) }\end{array}$ & 9 & $45.0 \%$ & 1 & $16.7 \%$ & 2 & $50.0 \%$ & $* * 0.695$ & NS \\
\hline & $\begin{array}{l}\text { Diabetic } \\
(\% \text { HbA1c } \geq 6.5)\end{array}$ & 7 & $35.0 \%$ & 4 & $66.7 \%$ & 2 & $50.0 \%$ & & \\
\hline
\end{tabular}

NS = none significant

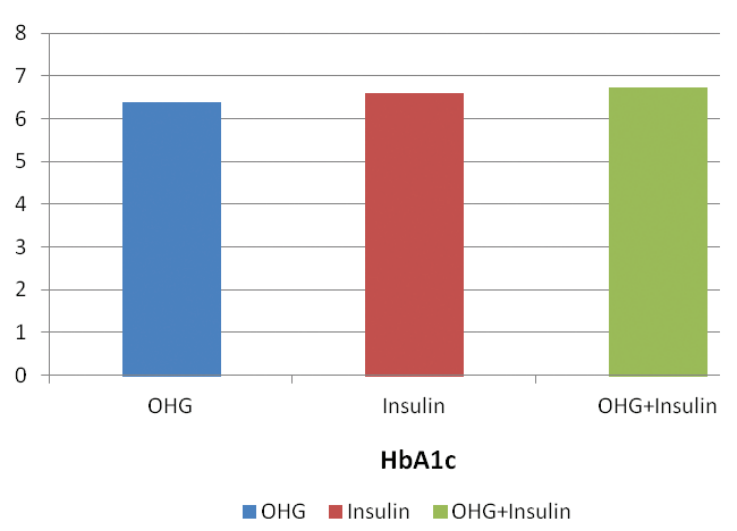

Fig 6: Comparison between patients with different treatment regimen as regard mean level of HBA1c at 6 months follow up after surgery. 


\section{Discussion}

T2DM is considered to be a highly prevalent chronic disease with limited major treatments. Bariatric surgery is suggested as an alternative treatment for T2DM that has possibilities to induce remission of the disease. In 2011, the International Diabetes Federation (IDF) stated that bariatric surgery could be used in obese patients with a BMI $>40 \mathrm{~kg} / \mathrm{m}^{2}$ and that it might bring benefit to obese T2DM patients with a relatively low BMI (BMI 30 35 $\mathrm{kg} / \mathrm{m}^{2}$ ), who do not respond to the usual medical therapies. ${ }^{8}$

However, the effects of bariatric surgery for nonobese T2DM patients have not been established. Although past studies predominantly focused on the role of bariatric surgery in patients with $\mathrm{BMI}<35 \mathrm{~kg} / \mathrm{m}^{2}$, patients with $\mathrm{BMI}<30 \mathrm{~kg} / \mathrm{m}^{2}$ were occasionally included in many studies. ${ }^{9}$

The results of this study points to the fact that LSG can play a remarkable role in managing T2DM obese patients. Our study revealed a highly significant reduction in the mean value of $\mathrm{HbA1C}$ at 3 and 6 months after surgery $(P<0.001)$. These findings are comparable to those of Wei-Jee Lei et al. who showed that out of 20 diabetic patients type 2 who underwent LSG; median reduction in HbA1c was from $10.1 \%$ to $7.1 \% .{ }^{10}$

The fact that $56.7 \% \quad(n=17)$ of our patients showed either complete remission (5/30 patients completely cured from T2DM) or improvement (12/30patients became pre-diabetic) of the disease 6 months after LSG; is keeping with the concept that LSG could be a potential option for the management of T2DM in obese patients.

Our results were in agreement with those of Guo et al. who conducted a study that included 34 obese patients with T2DM and BMI less than 40 $\mathrm{kg} / \mathrm{m}^{2}$ who underwent LSG. The clinical data and 3-year follow-up outcomes regarding remission of diabetes was retrospectively analyzed. It showed the complete remission rate of diabetes at $6,9,12,24$ and 36 months was $33.3 \%(8 / 24)$, $50.0 \%(12 / 24), 54.2 \%(13 / 24), 45.8 \%(11 / 24)$ and $50.0 \%(12 / 24)$, respectively. That study confirms the efficacy of LSG in the treatment of T2DM patients with a BMI less than $40 \mathrm{~kg} / \mathrm{m}^{2}{ }^{21}$ In addition, Abbatini et al. showed $80.9 \%$ resolution of T2DM after LSG over a 3-year follow up. ${ }^{12}$

With regard to the effect of LSG on T2DM obese patients, in another review that analyzed 27 studies and 673 patients, it was stated that diabetes resolved in $66.2 \%$ of the patients, improved in $26.9 \%$ of the patients, and was unchanged in $13.1 \%$ of patients. The mean decrease in $\mathrm{HbA1c}$ levels after an LSG was $-1.7 \%{ }^{13}$
Although the mechanisms underlying T2DM remission following LSG is not fully determined, some studies have reported favorable changes in insulin sensitivity. Improvement in insulin sensitivity could be attributed to decreased body weight, decreased calorie intake and reduction in inflammatory mediators. ${ }^{12,14}$ Some believe that hormonal regulation plays a key role. Recent studies have shown that LSG is associated with a marked reduction of ghrelin secretion, which is produced by the gastric fundus and is involved in mealtime hunger regulation. Moreover, ghrelin is known to exert several diabetogenic effects (increase in growth hormone, cortisol, and epinephrine). Therefore its suppression could contribute to improved glucose homeostasis. ${ }^{15}$ Interestingly, Peterli et al. measured higher GLP-1 levels following LSG. ${ }^{15}$

Undoubtedly, bariatric surgery is now becoming a viable treatment option for T2DM in obese patients, with recent large studies showing its superiority over traditional medical therapy. ${ }^{16}$ However, there is still a lack of large scale studies observing LSG in particular when it comes to diabetes resolution. This is due to the fact that Roux enY gastric bypass (RYGB) remains the gold standard bariatric procedure, with a T2DM remission rate reaching as high as $60 \% .{ }^{17}$ However, recent evidence has been emerging showing no significant difference between LSG and RYGB in treating T2DM, with both procedures showing comparable results in diabetes control. ${ }^{15}$ Another prospective study conducted by Vidal et al. on the changes in glucose homeostasis in 35 severely obese T2DM subjects undergoing laparoscopic SG (LSG) and 50 subjects undergoing laparoscopic Roux-en-Y gastric bypass (LRYGBP); showed at 4-months after surgery, T2DM had resolved respectively in $51.4 \%$ and $62.0 \%$ of the LSG and LRYGBP operated subjects $(P=0.332)$. That proved that LSG and LRYGBP result in a similar rate of type $2 \mathrm{DM}$ resolution at 4-months after surgery. ${ }^{18}$

The current study revealed insignificant difference in $\mathrm{HbA1C}$ reduction and T2DM resolution among patients with different treatment regimens. This suggests that LSG might prove to treat the disease regardless of the severity.

Our study has few limitations; first, number of studied patients was relatively small. Second, short term follow up for 6 months only. Third, other co-morbidities like hypertension and hypercholesterolemia were not evaluated.

In conclusion, LSG seems to be a restrictive procedure, but it also appears to induce significant changes in glucose homeostasis regardless of the pre- operative type of hypoglycemic medications. 
These data confirm LSG contribution to improve and induce remission in Type 2 DM obese patients regardless of the severity of the disease.

\section{Conflicts of interest}

No conflicts of interests

\section{References}

1. Aureo LD, Alessandro RS: Surgical treatment of type 2 diabetes in patients with BMI below 35: Mid-term outcomes of the laparoscopic ileal interposition associated with a sleeve gastrectomy in 202 Consecutive cases, $\boldsymbol{J}$ Gastrointest Surg. 2011; 16: 967-976.

2. Kral JG, Näslund E: Surgical treatment of obesity. Nature Clinical Practice Endocrinology \& Metabolism. 2007; 3: 574-583.

3. Hanusch-Enserer U, Cauza E, Brabant G, Dunky A, Rosen H, Pacini G, Tüchler H, Prager $\mathrm{R}$, Roden M: Plasma ghrelin in obesity before and after weight loss after laparoscopical adjustable gastric banding. J Clin Endocrinol Metab. 2004; 89: 3352-3358.

4. Silecchia G, Boru C, Pecchia A, et al.: Effectiveness of laparoscopic sleeve gastrectomy (first stage of biliopancreatic diversion with duodenal switch) on comorbidities in super-obese high-risk patients. Obes Surg. 2006; 16: 1138-1144.

5. Buchwald H: A bariatric surgery algorithm. Obes Surg. 2002; 12: 733-46.

6. WHO. 2006: "BMI classification". Global Database on Body Mass Index. Retrieved July 27, 2012.

7. Gumbs AA, Gagner M, Dakin G, Pomp A: Sleeve gastrectomy for morbid obesity. Obes Surg. 2007; 17: 962-969.

8. Dixon JB, Zimmet $P$, Alberti KG, Rubino F: Bariatric surgery: An IDF statement for obese Type 2 diabetes. Diabetic Medicine. 2011; 28: 628-642.

9. Li Q, Chen L, Yang Z, Ye Z, Huang Y, He M, et al.: Metabolic effects of bariatric surgery in type 2 diabetic patients with body mass index < 35 kg/m2. Diabetes Obes Metab. 2012; 14: 262-270.
10. Lee WJ, Ser KH, Chong K, et al.: Laparoscopic sleeve gastrectomy for diabetes treatment in nonmorbidly obese patients: Efficacy and change in insulin secretion. Surgery. 2010; 147: 664-669.

11. Guo $Y, X u X$, Wu A, Du J, Dong G: Effect of laparoscopic sleeve gatrectomy on type 2 diabetes mellitus in obese patients with body mass index less than $40 \mathrm{~kg} / \mathrm{m}^{2}$. Zhonghua wei chang wai ke za zhi= Chinese Journal of Gastrointestinal Surgery. 2017; 20:400-404.

12. F. Abbatini, M. Rizzello, G. Casella, G. Alessandri, D. Capoccia, F. Leonetti, and N. Basso: Long-term effects of laparoscopic sleeve gastrectomy, gastric bypass, and adjustable gastric banding on type 2 diabetes. Surgical Endoscopy. 2009; 24: 1005-1010.

13. Gill RS, Birch DW, Shi $X$, et al.: Sleeve gastrectomy and type 2 diabetes mellitus: A systematic review. Surg Obes Relat Dis. 2010; 6: 707-713.

14. Rizzello M, Abbatini F, Casella G, et al.: Early postoperative insulin-resistance changes after sleeve gastrectomy. Obesity Surgery. 2010; 20: 50-55.

15. Peterli R., Wölnerhanssen B., Wölnerhanssen B: Improvement in glucose metabolism after bariatric surgery: Comparison of laparoscopic roux-en-Y gastric bypass and laparoscopic sleeve gastrectomy: A prospective randomized trial. Annals of Surgery. 2009; 250: 234-241.

16. Schauer P, Kayshap S, Wolski K, et al.: Bariatric surgery versus intensive medical therapy in obese patients with diabetes. $\mathbf{N} \mathbf{E n g l} \mathbf{J}$ Med. 2012; 366: 1567-1576.

17. Blacktstone R, Bunt J, Cortes M, Sugerman $\mathrm{H}$ : Type 2 diabetes after gastric bypass: remission in five models using $\mathrm{HbA1C}$, fasting blood glucose, and medication status. Surg Obes Relat Dis. 2012; 8: 548-555.

18. Vidal J, Ibarzabal A, Nicolau J, Vidov M, Delgado S, Martinez G, Balust J, Morinigo R, Lacy A: Short-term effects of sleeve gastrectomy on type 2 diabetes mellitus in severely obese subjects. Obesity Surgery. 2007; 17: 10691074. 